\title{
OPINION
}

\section{Present Challenges Besetting the Iranian Academia}

\author{
Farid Rahimi ${ }^{\mathrm{a}}$ and Amin Talebi Bezmin Abadi ${ }^{\mathrm{b}}$ \\ ${ }^{a}$ Research School of Biology, The Australian National University, Canberra, Australia \\ ${ }^{\mathrm{b}}$ Department of Bacteriology, Faculty of Medical Sciences, Tarbiat Modares University, Tehran, Iran
}

Received for publication September 23, 2019; accepted October 29, 2019 (ARCMED_219_854).

In 2016, a handful of reports published in Science and $\mathrm{Na}$ ture $(1-3)$ highlighted some of the ethical issues concerning the Iranian academic output. While we maintain that the phenomena underlying these reports are inherently multifaceted $(4,5)$ and emphatically value constructive criticism and self-reflection, we feel prompted to highlight three key threats presently overclouding the Iranian academic ambience.

First, we must not rest on our laurels, which could easily transmogrify into threats. The Web of Science citation-indexing platform registered approximately 300 scientific articles published by Iranian academics in 1990 , but 56,500 by the end of 2018 —an almost 190 -fold record increase over almost three decades. This increasing rate in Iranian publication records reportedly translates into the first ranking among the MiddleEastern countries-with 54,388 articles and 28,813 citations in 2017 according to the SCImago Journal and Country Rank portal. However, continually braggingly reflecting on this ranking likely breeds a false or fragile sense of security that could inevitably threaten motivation and commitment to enduring national and international academic proactivity. Our laurels could become Achilles' heels of productive Iranian research, which relies heavily on the human workforce-the scientists, academics, undergraduate, or graduate students, the powerful arms of academic enterprise. Thus, encouraging, supporting, fostering, and upholding this human resource nationally are more paramount than constantly savoring past achievements.

Second, the burgeoning Iranian scientific output has become assertively tangible, steadfast, and still rising despite almost 19 series of international sanctions imposed on Iran in the last 40 years. Following the Iranian

Address reprint requests to: Amin Talebi Bezmin Abadi, Department of Bacteriology, Faculty of Medical Sciences, Tarbiat Modares University, P.O. Box 14115-111, Tehran, Iran; Phone: $(+98)$ (21) 82884883 or (+98) (21) 8288 4803; E-mail: Amin.talebi@modares.ac.ir
Revolution of 1978 and the stifling sanctions that followed, the Iranian scientific workforce suffered more than other sectors of the society. Participation in international conferences became highly constrained; myriads of scientific instruments were banned or became inaccessible; and rejections or boycotting of submitted articles affiliated with Iran-funded research or medical institutions followed by certain editorial boards, some journals, or publishers because of confused or unjustified reasons (6). Following the nuclear agreement (Joint Comprehensive Plan of Action; JCPOA) between Iran and the five permanent members of the United Nations Security Council effective from October 18, 2015, some academics hoped that new fields for scientific collaborations would open. However, scientific output continued steadily independent of the global politics. Interestingly, we believe withdrawal of the United States from JCPOA in May 2018 has had or will have no positive or negative impact on Iranian scientific output; thus, debating this outcome locally is pointless and must not distract the Iranian academic focus. Notwithstanding the historic global politics hindering basic and medical research, Iranian researchers and academics continued persistently-and enthusiastically-while upholding and fostering their international research collaborations. And we hope that this will continue under locally supportive ambience with the academics keeping focusing on what they do best.

Third, retractions of scientific articles is the most recent and multifaceted threat (5) that needs passionate deliberation by Iranian academics and researchers. The rate of Iran-affiliated English-written article retractions currently stands at an alarming 14 per 10,000 (7). Retraction Watch reported that fake peer-review and duplicate publications are the two most influencing causes accounting for increased retraction rates (43\%), but this could be an underestimation if articles published in Farsi also were included (7). Almost half of the retractions were likely due to reasons that could have been disallowed easily by the researchers. For example, publishing an article twice can easily be barred by everyone involved in the Iranian 
academia. The alarming news of retractions coincided with a Nature report, claiming that some Iranians have ghost-authored their scientific articles and purchased them using street markets (2). This claim can easily be disputed because more than ninety-thousands of Iranian faculty members cannot collectively rely on only some companies to ghost-publish their papers under disparagingly unethical norms (8). Nonetheless, criminalizing such activities by law (8), and personal and institutional upholding and establishment of ethical norms will progressively shut the ghostpublishing avenue.

Lastly, in prospect, we hope that current rising trends of Iranian publication records will continue and that the undeniable Iranian arm of knowledge and education-its creative scientific workforce-will see better days for their scientific productivity, in the Middle-East and beyond.

\section{References}

1. Rezaee-Zavareh MS, Naji Z, Salamati P. Creating a culture of ethics in Iran. Science 2016;354:296.

2. Stone R. In Iran, a shady market for papers flourishes. Science 2016; 353:1197.

3. Callaway E. Publisher pulls 58 articles by Iranian scientists over authorship manipulation. [Updated 2016]. https://www.nature.com/ news/publisher-pulls-58-articles-by-iranian-scientists-over-authorshipmanipulation-1.20916. Accessed November 3, 2016.

4. Jakubowski H, Xie J, Kumar Mitra A, et al. The Global Ethics Corner: foundations, beliefs, and the teaching of biomedical and scientific ethics around the world. Biochem Mol Biol Educ 2017;45:385-395.

5. Brainard J. Rethinking retractions. Science 2018;362:390-393.

6. Arie S. Unintended consequences of sanctions against Iran. BMJ 2013;347:f4650.

7. Oransky I. Volunteer watchdogs pushed a small country up the rankings. Science 2018;362:395.

8. American Association for the Advancement of Science. News at a glance. Science 2019;364:712-714. 